feeling in his eyes. His refraction and fundi were normal. $\mathrm{He}$ wore the ordinary presbyopic reading glasses. I ascertained that he wore fairly dark glare glasses most of the day. On discontinuing their use, his symptoms at once disappeared.

Remarks.-My attention was first drawn to this point by the effects of glare glasses on my own eyes many years ago. After their use I got headaches, and my eyes were very sensitive to light. I gave them up over eighteen years ago and have never again used them: The case recorded is one of eight cases amongst officers who had a similar complaint and who got rid of all their symptoms on discarding their glare glasses. Myopes seemed to be immune from those bad 'effects, and on the contrary obtained relief from their use. The average man usually uses fairly dark glasses, and no doubt this leads to a greater strain on the accommodation. Severäl motor drivers in the R.A.S.C. have told me that they do not use their goggles as they gave them headaches. The rapid relief of symptoms was so remarkable in all the cases that $\mathrm{I}$ consider the trouble was due to the glare glasses and was not a mere coincidence.

In conclusion, I wish to express my thanks to Captains Doyne and Spencer, the ophthalmic specialists of Baghdad and Amara respectively, for much of the information contained in this report.

\title{
ADDITIONAL NOTE ON FREE INSTILLATION OF COCAIN WITH ADRENALIN, AND OF ESERIN IN CATARACT EXTRACTION
}

\author{
BY \\ H. Herbert, Lt.-Col., I.M.S. (Retd.), \\ NOTTINGHAM
}

SINCE the writing of the inconclusive paper published in the April (1919) issue of this Journal, p. 152, the free use of cocair with adrenalin has been continued. And it has been generally followed by repeated instillation of eserin, after simple or " modified simple" extraction. The experience, as a whole, relates to 600 cataract extractions.

- There is one definite practical observation to be recorded, apparently of some value. So far as I could judge, sensation in the iris disappears under cocain and adrenalin instillation, step by step with the reaction of the pupil to light. In testing the reaction a lens has been used to focus the light from the window on the pupil, the patient lying ready for operation, only the one eye being opened for the test. The progressive loss of pupillary activity 
under the influence of these drops seems to afford a much closer indication of the state of sensibility of the iris than does the accompanying dilatation of the pupil. The size of the pupil when its motility disappears entirely, together with complete loss of sensation of pain in the iris, varies somewhat in cataract patients, possibly owing to varying minor grades of rigidity of pupil.

One could be confident that there would be no display of feeling in operating upon the iris only when the pupillary reflex had been quite abolished. We all know that many patients at quite a low stage of local anæsthesia seem to feel very little pain when their iris is pulled upon, or squeezed, or cut. We are not concerned with this. We are concerned with the sure and invariable elimination of all dangerous movements of lids and globe in operating among a sensitive and excitable people.

At one time we found some difficulty in ensuring full anaesthesia of the iris. This was apparently due to staleness and consequent ineffectiveness of our supply of adrenalin chloride solution. In one instance, after three adrenalin instillations among 4 per cent. cocain instillations repeated every three minutes for an hour, the pupil was still fairly small and active, and the operation had to be performed with the iris correspondingly sensitive. In our operations with maximal perchloride irrigation of the conjunctiva, the use of adrenalin is more imperative than in the practice of others.

Practical application was made of the above observation. It enabled us to divide up the patients into two groups for differential treatment according to our estimate of their self-control. In patients at all likely to prove "squeezers" full anaesthesia was considered advisable. This entailed combined extraction, since it was found that the wide fixed pupil of complete anaesthesia could not be fully contracted afterwards by eserin in time to guard against iris-prolapse.

In the somewhat smaller group of patients who seemed likely to bear a little pain without movement, and to keep their eyes quiet after operation, the simple method was attempted, though the attempt was not always successfully carried out. The operation was begun when the pupil was still in some degree active, though considerably dilated. With the pupil in this state we expected to produce full miosis afterwards with eserin, without symptoms of eserin poisoning appearing. Finally, however, a small prolapse occurred after a simple extraction performed with slightly active pupil. Eserin had been instilled seven times after operation, but the size of the pupil could not then be seen, owing to blood in the anterior chamber. A feeling of nausea was coming on. After this the pure simple method was given up. It was recognised that in order to be secure against prolapse in Indian hospital practice, either less cocain must be used, and the 
(simple) operation performed with the pupil but little enlarged, or some form of excision or incision of iris must be always practised. The latter alternative was selected, frequent use being made of Elschnig's small basal iris-puncture.

One is in rather a dilemma when from any reason one has to operate upon a pronounced "squeezer" with the iris still obviously sensitive, i.e., with the pupil still fairly small and active. In such cases I have successfully substituted radial division of the iris for iridectomy. While the assistant holds the speculum forward off the eye, and draws the eyebrow well up on the frontal bone, after Smith, the iris is exposed by seizing the conjunctival flap with the fixation forceps and pulling it downwards. The iris is then cut with the points of de Wecker's scissors directed straight backwards. The necessary two or three small scissor-snips appear to be decidedly less painful than pulling the iris out of the 'wound, and excising a portion of it. And if the patient should attempt to squeeze, rolling up the eye, the conjunctival 'flap is readily released and the direction of the scissor blades is such that they cannot do much harm. They cannot well be caught in the corneal wound. The scissor points cut into the lens. On this account the procedure is not very well suited to Morgagnian cataracts. But in ordinary cases I feel inclined to try it extensively, to replace iridectomy, to obtain the narrowest possible of complete colobomata.

Upon eight occasions in which 1 per cent eserin was used, symptoms of poisoning supervened-stomach pain with vomiting, following upon nausea and faintness. In six other instances nausea and faintness alone' were felt. In one feeble patient nausea was experienced after only four instillations of eserin, so that this drug could scarcely have been alone responsible. Another weakly patient vomited once or twice in the evening after combined extraction without eserin. Here free cocain instillation alone appeared to be the cause, and probably in other cases the cocain was partly responsible, directly or indirectly. Possibly the vaso-constrictive action of prolonged cocain and adrenalin instillation on the mucous membrane of the lacrymal passages may have considerably facilitated the flow, both of cocain and of eserin drops, into the nose. (The flow. was not facilitated by voluntary lid-movements, as the lids were kept closed between the instillations.)

In a case of linear extraction (curette evacuation) in a young patient, I was much struck with the extremely wide dilatation of pupil seen next day, as a result of the use of atropin after operation, following upon free cocain and adrenalin instillation before operation. If in senile cataract extraction by the simple method anything nearly approaching this extreme dilatation were obtainable, the prevention of iris-prolapse would .probably be more certain than by the use of eserin. Since returning to this country in April, 1919, I have been 
endeavouring to obtain such dilatation. The difficulties are (1) the tendency to contraction of the pupil due to the low pressure in the eye from leakage through the large wound, and (2) more or less rigidity of the pupil in old people. Using adrenalin, then atropin, then cocain and again atropin, and then repeated cocain instillations a very wide dilatation can be obtained, powerful enough to persist but slightly changed after the cataract incision has been made. At present I am operating thus, sometimes by simple, sometimes by modified simple extraction. Atropin is again instilled twice after operation.

The method has not been very successful in preventing prolapse, but such prolapses as have occurred have been extraordinarily small.

All of these patients upon whom free cocain instillation has been practised with adrenalin, have their heads raised upon pillows or upon an inclined plane until the evening of the operation day, because of the suggestion of tendency to haemorrhage made in the paper already published.

\title{
OBSERVATIONS ON THE WEIGHT, VOLUME, AND ASH OF HUMAN LENSES.
}

\author{
BY \\ F. P. MAYNARD, M.B., F.R.C.S.Eng., \\ L.T.-COLONEL, I.M.S., RETD. \\ Calcutta.
}

IN Volume III of the Transactions of the Ophthalmological Society of the United Kingdom, a paper, by Mr. Priestley Smith, appeared "On the Growth of the Crystalline Lens," in which the weight and volume of lenses removed in their capsules post-mortem, and supposed to be clear, were recorded by means of an apparatus designed for the purpose. The author established the fact that the lens increases in weight and volume throughout life, averaging $1.5 \mathrm{mgm}$. increase in weight and $1.5 \mathrm{c} . \mathrm{mm}$. increase in volume for each year of life from the age of 20 to 70 . Apart from some valuable observations on the specific gravity of the lens, its diameter, the increasing weakness of the hyaloid membrane in older lenses, and the probable cause of hypermetropia acquisita, which are very interesting but do not concern us at present, $\mathrm{Mr}$. Priestley Smith found cataractous opacities in 28 out of the 163 lenses examined. These were found more often, and to a greater degree, as the age of the patients advanced, as one would expect. Two of the eataracts were complete (ripe); of the rest, 22 were cortical, only four being nuclear. In India, the nuclear opacities would have outnumbered the cortical. 